\title{
JIYAN DI RÊYA WELATPAREZÎYÊDA \\ Kurtejîyana Knyaz îbrahîm Mîrzoyev
}

\section{Hayreddin KIZIL ${ }^{*}$ \& Naci KARAGÖZ ${ }^{* *}$}

Hejarê Şamîl-Medîna Knyaz, 2007, Almatı, (183 rûpel)

Dema mirov pirtûkeke ku li welateke biyanî çap bûye dixwîne, hînî gelek tiştan dibe. Bi taybet gava mijara pirtûkê jiyana kesekî/ê be. Mijara pirtûkê çi welatê ku li wir dijî çi serpêhatiyên wî be di her warî de agahî jî zêdetir dibe. Mijara pirtûka ku em ê binasînin derheqê jiyana Kurdekî rewşenbîr û akademisyenek de ye ku rengê jiyana wî sirgûn û serkeftin e. Pirtûk, jiyana Knyazê Îbrahîmî ya bi sirgûn lê bi serkeftî dide ber xwendevanan.

Pirtûk ji aliyê du nivîskaran ve hatiye nivîsandin. Yek ji wan nivîskaran Hejarê Şamîl e, kurê hevalê Knyaz Îbrahîmî e (r. 8-9). Herdu nivîskar ji bo nivîsandina pirtûkê, ji arşîva Knyazê Îbrahîmî jî sûd wergirtiye (r. 40). Nivîskar Hejarê Şamîlî, wiha nivîsandiye: "Armanca min ne nivîsandina bîyografîya Mamoste Knyaz e. Bi vê pirtûkê xwesteka min mudaxeleyeke dilnizm e, ji bo çîrokê jiyana wî ku bi jandariya kurdên Sovetê re hevdeng e (r. 9).

Knyaz Îbrahîm Mîrzoyev niha li Qazaxistanê dijî. Rojhilatzan, kurdzan, rexnevanê wêjeyê, doktorê zanistên fîlolojiyê, profesor û akademisyen e. Di Zanîngeha Qazaxistanê ya Dewletê ya Almatê de serekê Navenda Zimanên Cîhanê ye. Dîsa serekê Yekîtîya Kurdên Qazaxistanê, bi navê Berbangê ye (r. 4). Di heman demê de Knyazê Mîrzoyev endamê PENa Kurd e û li Almatê serredaktoriya kovara "Nûbar"ê dike (r. 4). Knyaz Îbrahîm Mîrzoyev di 22ê Cotmeha 1998an de ji ber xizmeta xwe ya di hêla civakî û perwerdeyê de, madalyaya “Hurmet”ê ya Komara Qazaxistanê wergirtiye. Xebatên wî yên ji bo zimana kurdî jî hene. Di sala 2006an de pirtûka wî ya bi navê "Zimanê Kurdî" ku du cild in derketiye. Ev pirtûk ji bo dibistanan ji bo komên 2-5 û 6-9an hatiye amadekirin. Knyazê Îbrahîmî ji bo polên ji 2 heya 9an, "Bername û Rêberiya metodîkayê ji bo mamosteyê zimanê kurdi” jî amade kiriye (r. 5).

Pirtûk bi çend taybetmendiyên xwe ve balkêş e:

\footnotetext{
*Yrd. Doç. Dr, Dicle Üniversitesi, Öğretim Üyesi

** Dicle Üniversitesi, Kürt Dili ve Edebiyatı Tezsiz Yüksek Lisans Öğrencisi

† Belê weke kovara Nûbiharê ku ji bîst û sê sal e li Türkiye’yê weşana xwe didomîne. Kovara Nûbarê jî li Qazaxistanê bi salan e tê weşandin.
} 
1- Sirgûn: Berhem, nîşan dide ku jiyana Knyazê Îbrahîm bi sirgûnê dest pê kiriye. Bavê Knyaz, Îbrahîmê Nevo, di 15 salîya xwe de, di sala 1926an de bi kekê xwe Ebdûla (Evdo) re ketiye ser rêya sirgûniyê. Li Bakûrê Azerbaycanê li herêma Nexçîvanê bi cih dibe (r. 12). Kekên wî yên mezin li Türkiyeyê dimîne (r. 19).

Lê ne ji bo Knyazê Îbrahîm ne jî ji bo Kurdên li Rusyayê sirgûn naqede, piştî sirgûna ji Türkiyeyê vêca sirgûna li nava Rusyayê çêdibe. Bi biryara Stalîn di sala 1937an de bi hezaran Kurd ji Nexçîvan û Ermenîstanê tên nefîkirinê Qazaxistanê û Asya Navîn (r.21). Di nava sirgûniyan de malbata Knyazî jî heye. Sirgûna duyemîn a Kurdên li Rusyayê di 1990î de ye. Dema navbera Azerbaycan û Ermenîstanê de şer diqewime, kurdên Misilman ên Ermenîstanê ji Ermenîstanê tên sirgûnkirin.

Nivîskar, derbarê nexweşî û mirina sirgûnan a 1937an jî dike. Ji ber ku ev sirgûn beriya zivistanê dest pê dike ji serma û rewşa ji derê sihetê gelek nexweşî peyda dibin. Di nav wan de gele zarok û pîr û hin kesên din ji ber van nexweşînan rehmet dikin. Li gorî pirtûkê leşkeran laşê miriyan li îstasyonan ji vagonan dadixistin, ger wext heba çal dikolan û diavêtin navê, serî digirtin, lê dema ku li nêzî çem an jî golekî bidîtabana karê wan hêsantir dibû. Ji ber vana Kurdan nedixwestin miriyên xwe bidin leşkeran, di derheqe miriyan de agahî nedidan leşkeran. Ji bo ku wan dixwest li cihê ku ew biçinê li wir veşêrin, ji ber vê miriyên xwe di bin kelemelan da vedişartin. Lê belê ji ber ku roj bi roj bêhn ji laşê miriyan bilind dibû neçar diman ku di bin çetinahiya wê bêhnê rêwîtiya xwe bidomînin (r. 23). Ev rêwitiya mirinê piştî 20 rojan li Qazaxistan û Qirxizistanê bi dawî bû (r. 24).

Heya vê demê di derheqê sirgûnên Kurdan ên Rusyayê xebatek akademîk tune ye. Divê xebatek akademîk li ser vê mijarê were amadekirin. Nivîskar Hejare Şamîl di jêrenotan de navê hin berheman daye. Di rûpela 25an de navê berhemeke xwe jî daye (Hejarê Şamîl, “Kurdên Dîasporayê”, Weşanên Perî, Îstanbûl 2005)

Malbata Knyazê Îbrahîm li bajarê Kizilkayayê herêma Celalabad a Qirxizistanê tê bicihkirin (r. 25). Lê li wir pir namînin. Di salên ku şerê duyem ê cîhanê dest pê dike de, Wezîrî Nadirî ku di fermandariya leşkerî ya Qafqasê de dixebitî, tê Qirxizistanê û nezîkî 15 malbatên xizmên xwe paş ve dizivirîne Qafqasê. Ev malbat di destpêkê de li bajarê Êrîvanê tên bicihkirin (r. 26). Dûv re koçî gundê Rihanlîyê nehiya Masîsê dikin (r. 26). Knyaz Îbrahîm di 1947an de li Rihanliyê tê dinê (r. 27). 
Di pirtûkê de mijarên sirgûna ji Ermenîstanê û polîtîkaya Ermeniyan li ser Kurdan jî hene. Li gorî pirtûke Kurdên misilman ên li Ermenîstanê wek Rûsan, paşnavê wan bi -ov, yev, diqede. Kurdên Êzîdî jî wek Ermeniyan paşnavê wan bi “yan” diqede. Li gorî nivîskaran li Ermenîstanê bi vî rengî di navbera kurdan de veqetandineke sun'î hate efirandin (r. 101102).

Dema navbera Azerbaycan û Ermenîstanê de şer diqewime, Kurdên misilman ji Ermenîstanê tên sirgûn kirin. Hin şêxên êzidiyan ên bi polîtîkaya Ermeniyan lez dane wê propagandaya ku "Êzîdî ne kurd in" û ji bo kurdên misilman ji welêt werin derxistin dixebitin. Lê hin Kurdên mîna Şeref Eşîrî, Şekroyê Xudo, Têmûrê Xelîl, Karlênê Çaçanî, Semend Siyabendov, Xalit Çetoyev, Çerkezê Reş û bi dehan kesayetan di wê demê de li hember pevçûnên kurdên misilman û kurdên Êzîdî li ber xwe didin (r. 102, 103, 104).

Wê demê Knyazê Îbrahîm jî li hem ber van bûyeran disekine. Lê ew jî dikeve nav refên sirgûnê. Knyaz û malbata xwe di wê serdemê de ji Ermenistanê sirgûn dibin û piştî 6ê İlonê sala 1990î Knyazê Îbrahîm li Qazaxistanê bi cih dibin (r. 103, 104).

\section{2- Edebiyat û Perwerdehiya Kurdan:}

Pirtûk ji bo nêrinek li Dîroka Edebiyata Kurdî û perwerdehiya Kurdî li Rusyayê û li Paşqafqasê jî baş e. Xwîner bi vê berhemê, agahiyên derheqê hin nivîskaran û berhemên wan de dê bixwîne. Wek mînak di pirtûkê de derheqê xalê Knyazê Îbrahîmî, Wezîrên Nadîrî de agahî hene. Wezîrê Nadirî gelek klasîkên biyanî wergerandiye bo Kurdiya Kurmancî (r.13).

Di pirtûkê de derheqê kovara "Rya Teze" û perwerdehiya bi Kurdî de jî agahî hene. Rya Teze di 1930yî de bi herfền Latînî dest bi weşana xwe dike (r. 37). Di sala 1937an de tê girtin. Kovar, 18 sal girtî diminê lê 1955an de vê carê bi alfabeya Kîrîlî dîsa dest bi weşana xwe dike (r. 37).

Wek tê zanîn demekê li Rûsyayê perwerdehiya Kurdan bi Kurdiya Kurmancî bû. Li gorî pirtûkê di sala 1934an de li Ermenistanê jimara dibistanên Kurdan gihiştiye 45an. Di van dibistanan de 2365 xwendekar perwerde dibûn (r. 30). Lê di sala 1937an de wek kovarê dawî li dersdayîna Kurdî tînin (r. 30).

Ji bilî van mijarên derheqê xebatên Kurdî û Kurdolojiyê li Azerbaycanê, (r. 81-84), xebatên perwerdehiya Kurdi li Qzaxistanê de jî hene. (r. 121-122). Di pirtûkê de navên 
berhemên ku van salên dawî derketine jî hatine nivîsîn. Navên pirtûkên kurdî ku piştî 1990an li Azerbaycanê hatine çapkirin di rûpela 83 û 84 an de hene. Navên hin pirtûkên Kurmancî ku li Almatê hatine çapkirin jî di rûpela 116 û 117 an de hene.

Di nav van berheman de navên pirtûkên Knyazê Îbrahîmî jî hene. Pirtûka "Zimanê Kurdî ji bo Komên 2-5 û 6-9" gelek balkêş e. Ev pirtûk bi erêkirina Wezareta Zanistî û perwerdeyê ya Qazaxistanê hatine çapkirin û li dibistanên Qazaxistanê weke dersên zimanê kurdî ku fermî bûne, tên xwendin(r. 120-121). Divê weşanxaneyên li Türkiyeyê yan ji van welatan pirtûkan bînin yan jî heman pirtûk ji vir jî bên çapkirin.

Di pirtûkê de mijareke balkêş heye. Bavê Knyaz, Îbrahîmê Nevo, bi xwe ji eşîretên Kurdan, ji Celaliyan e (r. 16). Nivîskar wisa dibêje:

"Navê Celaliyan, di dîrokê de bi Koroxlî ji tê naskirinê. Koroxlî (Rewşenê Elo) ku gelên Rojhilata Navîn û Qafqasê ew weke qehremanên xwe yên neteweyî qebul dikin û anîne halê efsaneyê, di sedsala 16an de jiyaye û weke di gelek belgeyan de îsbat dibe ji eşîra Kurdan a Celaliyan derketiye (r. 18).

Di cihekî de ji destana Koroxlî hevokek heye: “Ez Kurd im, kurê Koroxlî me..” (r. 14).

Li Türkiyeyê heya niha xebatek derheqê destana Koroxlî de me nedîtiye. Divê lêkolinvanên Kurd ên Türkiyeyê li ser vê mijarê bixebitin. Hejarê Şamîl di rûpelên 18-19an de derheqê Koroxlî de agahiyan dide.

\section{3- Azerî û Kurdan, Qazax û Kurdan}

Berhem ji bo têkiliyên di navbera gelên Azerî û Kurd, Azerî û Qazax jî agahiyan dide. (Derheqê têkilî û dostaniya Azerî û Kurdan r. 43, 44 û r. 72-81)

Ji xwe di destpêka pirtûkê de ji devê Knyaz, ev hevok hatine nivîsîn: "Dayika min Kurd bû, lê min qasî diya xwe hez ji dayikên, Azerî, Qazax, Rûs û Ermeniyan kir. Min ziman û derfetên wan bi kar anî û ez mezin bûm û gihîştim vê şûngehê. Dayika min şîr da min, ez firê xistim, lê wan per dane min ez dinêxistim.” (r. 3)

Li gorî pirtûkê dema malbata Knyazê Îbrahîm ji Qazaxistanê bi alîkariya Nadîrov vedigerin li gundekî niştecih dibin. Ji sedî 80ê nifûsê vî gundî, Rihanliyê, Azerî bûn. Knyaz, li vî gundî dest bi xwendina xwe dike. Gava ku dest bi dibistana seretayî dike bi Kurmancî tenê 
dizane. Lê di xwendina xwe de hem hînî zimanê Azerî hem jî hînî Ermenîkî û Rusî dibe (r. 30). Mijara teza wî jî têkiliyên Azerî û Kurdan e. Navê teza Wî "Têkiliyên Wêjeyî yên Azerbaycan û Kurdan” e (r. 73).

Nivîskar derheqêe kurdên Qazaxistanê de jî agahiyan didin. Diroka Kurdan a li Qazaxistanê ji sirgûna dema Stalîn dest pê dike. Ango diroka wan a li vî welatî 70 sal in. Li gorî nivîskaran di sala 1937an de di encama polîtîkaya despotîk a Stalîn de, gava ku Kurd ji Qafqasê sirgûnê vir kirin, Qazaxan hembêza xwe ji Kurdan re vekirin, wan jî dil dane Qazaxan (r. 123).

Qazaxistan piştî hevberdana Yekîtiya Sovyetê di 1990an hatiye ava kirin. Di vî welatî de mafên kurdan heye. Mafên kurdan ên civakî, aborî û çandî qasî mafên gelî Qazaxî ji hêla dewletê ve tê parastin. Hûn gava di nava bajarê Almatê de bimeşin, hûn ê şahidê xeberdana ji dehan zêdetir zimanan bibin. Kurdên ku li Qazaxistanê ne Kurd in, Çeçen Çeçen in, Azerî jî Azerî ne (r. 123).

Beşa Kurdolojiyê ya li Qazaxistanê van salên dawî pêş de çûye. Navdarên kurdnas û nivîskar dibêjin "Qazaxistanê di van salên dawî de ûnvana navenda kurdolojiya berê ya li komarên Sovyetê qezenc kiriye. Di 14ê Cotmeha 2006an de li bajarê Qazaxistanê li Almatê, bi pêşengiya Knyazê Îbrahîm konferansa navneteweyî ya kurdan bi navê "Neteweya Kurd: îro û Pêşeroj de" pêk hatiye (r.125).

Wek nivîskar jî dibêjin ev behrem bi jiyana Knyaz Îbrahîm jiyana Kurdên li Rûsyayê jî li qelemê dide. Ji ber vê qasê yekî/ê ku bixwaze hem jiyana nivîskarekî akademîsyen bixwîne dê agahiyên din jî di vê pirtûkê de bibîne.

Lê wekî xwîner du pêşniyazên me hene:

1- Yek ji xwîneran re ye. Divê ji bo hişmendî, rewşenbîrîya Knyaz Îbrahîm bê fêm kirin divê xwîner beriya xwendina pirtûkê, hevpeyvîna Hejarê Şamîl ya bi Knyaz Îbrahîm re ku di heman pirtûkê de ye bixwînin (r. 160-178).

2- Pêşniyaza me ya duduyan hem ji bo nivîskarên vê pirtûkê hem jî ji nivîskarên din re ye: "Nivîskar dema biwêjek xwemalî bikar tînin bila ferhengokek di dawiya pirtûka xwe an jî gotara xwe ve kin. Bi vî awê hem peyv hinda nabin hem jî ji bo xwîneran têgihiştina mijaran hêsantir dibe." 
Hin peyvên ku di pirtûkê de tên bikaranîn: xuyang (r. 23), hişpak (r. 23, 41), hedirandin (r. 24), jiyana kolxoz (r. 37), gelale (r. 42), disewiyan (r. 45), rep bûn (r. 46), seqaya neteweperestinê (r. 46), bixerpişînim (r. 46), safoka ramana xwe (r. 41), gotin li dev (r. 52), dêlindêza binaxkirinê (r. 55), rûdêna Wî tirsdêr bû (r. 55), bêşayîş (r. 62-63, 88), rakêş (r. 93), şaşwaz (r. 94), îtîrazkar-liberrabûnêr, sewandin (r. 96), çonayetî (r. 96), pêşçavkirin (r. 98), çemka xwîn bi xwînê dihate meşandin (r. 100), berpêş kirin (r. 106), vehesîn (r. 132), çonayetî (r. 142), balrakêş (r. 134), rahejîyabû (r. 164), gelş (r. 166, 170), raderbirîn (r. 170), pijdana ramanê (r. 170), tilarî (r. 171), çespandin (r. 172, raser (r. 172). 